\title{
Moving from exploring on-farm opportunities with a single to a multi-year focus: Implications for decision making
}

\author{
J.M. RENDEL ${ }^{1}$, A.D. MACKAY ${ }^{2}$, P.N. SMALE ${ }^{1}$ and I.VOGELER ${ }^{2}$ \\ ${ }^{1}$ AgResearch, Private Bag 50034, Mosgiel, New Zealand \\ 2 AgResearch, Private Bag 11008, Palmerston North, New Zealand \\ john.rendel@agresearch.co.nz
}

\begin{abstract}
In pastoral grazing farm systems there is growing awareness of the importance of including year to year variation in pasture grown when analysing and designing appropriate and more profitable systems. Few authors have clarified how an optimal farm system incorporates inter-temporal variability. This paper shows for a Whanganui hill country sheep and beef farm, that inclusion of inter-annual variation in pasture growth rate results in a more dynamic farm system than when only average pasture production data are used in a new, multi-year farm optimisation model. The variation in stock numbers, sale dates and pasture covers were quantified, as was the variation in farm profitability (measured as Earnings Before Interest, Tax, Depreciation and Amortisation, EBITDA). Interestingly, there was only a small difference in Net Present Value between the two approaches over 10 year's simulation.
\end{abstract}

Keywords: farm systems, variability, INFORM, multiyear

\section{Introduction}

There is recognition that variation across years is important (Korte \& Rhodes 1993; Cacho \& Bywater 1994; Thompson et al. 2015; Vogeler et al. 2016), but most analysis of pastorally-based farm systems continue to use average rather than multiple year's data to explore changes to the system, the value of new technology and the implications of these to long-term performance (e.g., Bourdôt et al. 2012; Dynes et al. 2011; Chapman et al. 2013; Rendel et al. 2013, 2015; Vibart et al. 2015). This is recognised as a deficiency for any strategic analysis which invariably has impacts over multiple years, and when there is underlying variability over time in major on-farm resources (pasture and crop production), as well as prices. These changes (e.g., irrigation, conversion to another enterprise) invariably require capital investment (both for infrastructure development and capital livestock), which have income streams that vary over time due to fluctuations in climate (pasture production) and prices received for produce.

The inclusion of the initial investment in the farm systems analysis, along with the resulting cash-flows over time and terminal value at the end of the investment period within a farm optimisation model, would be a major step forward. It would provide an analytical capability to inform and aid understanding of both the value of on-farm investments and how they could be implemented. Combining the variability of pasture production due to climate, with that of the variation across the land management units (LMU's) of the farm and in the market place as it influences price, may further assist in identifying the risks and opportunities associated with current and future investments in the business.

The aim of this paper was twofold: to identify the potential value of moving from an average to an inter-temporal analysis of pastoral farm systems, and to outline what the farm systems may look like when accounting for inter-annual climate variation as it influences forage supply, compared to farm system based on average pasture growth rates. The approach taken is at a strategic level rather than operational or tactical.

\section{Methods}

INFORM (Rendel et al. 2013, 2015) was developed as a single year steady state optimisation model (linear programme) of a pastoral farm that allows a farm to be split into (near) contiguous areas that have similar attributes (Land Management Units, LMUs). The user provides input data about the resources available (land area, pasture and livestock performance including crops and nitrogen responses), costs (per hectare, per animal and enterprise) and prices (meat schedules) and INFORM identifies the optimal stocking and sales policies that maximise EBITDA. INFORM was further developed to include multiple years. Several changes were required for this to happen:

1. INFORM is no longer a single year steady state model.

2. INFORM identifies the entry stock policy at the beginning of the planning horizon and the exit strategy at the end of the planning horizon. Both the entry and exit stock policies are valued the same (IRD values).

3. Capital stock can be purchased or sold over the 


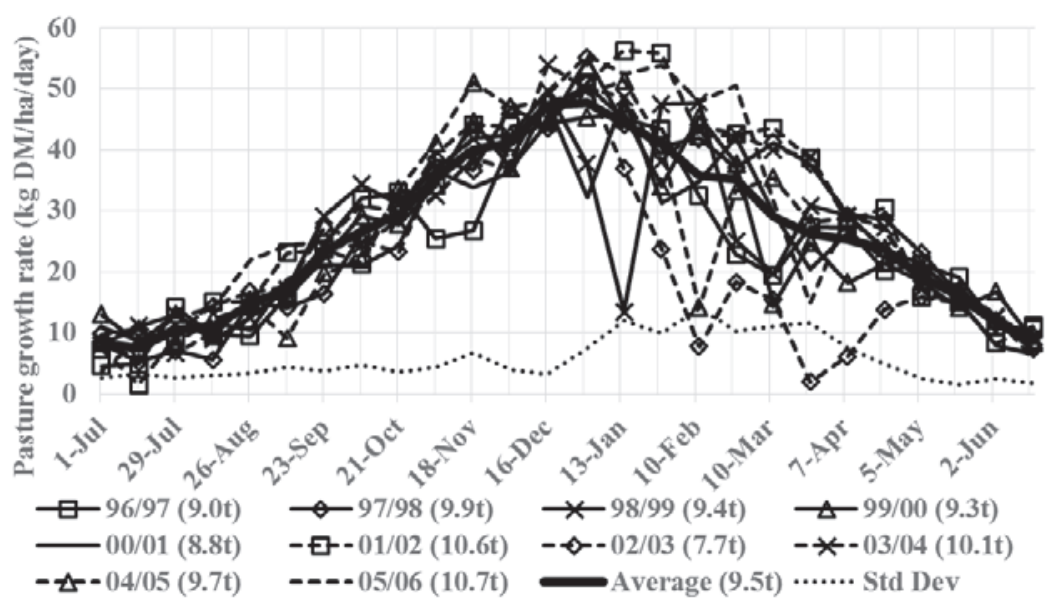

Figure 1 Fortnightly pasture growth rates (kg DM/ha/day) simulated by ASPIM for each of the 10 years. The standard deviation for each fortnight associated with the 10 years of pasture growth and the average for the 10 years simulated by APSIM, averaged over the 4 LMUs.

planning horizon, with the purchase price being set at $150 \%$ of stock valuation and sale price $50 \%$ of valuation, in an effort to represent scarcity of stock when purchased and over-supply at sale time.

4. INFORM objective was changed from maximising an annual EBITDA to maximising the discounted sum of the annual EBITDA including the purchase price of stock at the beginning of the planning horizon and the valuation of capital stock at end of the planning horizon. INFORM maximises the Net Present Value (NPV) over the planning horizon.

5. INFORM was enhanced to allow fortnightly pasture growth and energy content to vary across years.

At this stage of development costs and prices do not vary across years. These will be included in future enhancements to reflect the influence of climatic conditions in the months leading up to spring on the grass market, and of summer and autumn pasture growth on store prices and associated costs.

A Whanganui farm was used as the case study (Rendel et al. 2013, 2015). The farm is 508 ha, split into 4 LMUs. Climate data from NIWA virtual cells was fed into The Agricultural Production Systems Simulator (APSIM; https://www.apsim.info/) to generate 10 years of daily pasture growth data from 1 July 1996 to 30 June 2006 for each LMU. The LMUs were differentiated based on their Land Use Capability (Lynn et al. 2009). The individual daily pasture growth rates were then aggregated into fortnightly periods.

Two scenarios were analysed using INFORM:

1. Actual - used the pasture growth rates (PGR) over each of the 10 years simulated by APSIM, with a 5\% per annum discount rate.

2. Average - summed and averaged from the 10 years of actual PGR to calculate an average annual PGR profile and replicate that for each of the 10 years (i.e., 10 years each with same PGR profile) with a $5 \%$ discount rate.

The discount rate $(5 \%$ per annum) was based on the risk-free rate (see http:// www.treasury.govt.nz/publications/guidance/reporting/accounting/discountrates ). Whilst the risk-free rate for 10 years ahead is currently $3.21 \%$, as at 31 December 2010 the riskfree rate for 10 years ahead was $6.13 \%$.

These two options were chosen to gain an understanding of the difference between farm systems modelled using actual and average pasture production over 10 years. In both options a requirement was that at least 100 beef cows, as at $1^{\text {st }}$ July, were to be farmed to replicate the use of cows in hill country.

The fortnightly pasture growth rates for all years were similar from May to late October (Figure 1). From November to late April there was a wide range of PGR. This period is important for hill country farm systems as the pasture is not only used to finish young stock, it is required to grow replacement young stock and to set up sufficient feed to get through the winter. Whilst the total pasture produced in an average year is similar to one season (1998/1999) the pasture production pattern does not resemble any of the years.

\section{Results}

\section{Farm system}

The use of actual year to year rather than average pasture growth rate data in the multiyear version of INFORM resulted in a greater variation in ewe numbers between years (Figure 2). Ewe numbers ( $1^{\text {st }}$ July) varied from 4359-5330 over the 10 years when actual PGR were used in the model (Figure 2a). The fewest ewes present at weaning (3789) occurred in January 2001 after a period of poor pasture growth during November 2000. When an average PGR was used, ewe numbers remained within a narrow band (4739-5010) over the 10 years (Figure $2 b$ ). In both scenarios, two-tooths entered the flock when ewes were culled in late-February. Dry ewes were removed at the end of July after pregnancy scanning. In 3 of the 10 years ewes were sold with lambs at foot (in reality they would probably be sold earlier) and in one year, pregnant ewes were purchased when the actual year to year PGR were used (Table 1). 
When average PGR are used the same pattern was observed. However, in 8 of the 10 years, ewes were sold with lambs at foot in early October. The pattern of prime and store lamb sales were, not unexpectedly, quite different when actual rather than average PGR data were used in INFORM (Table 1). With actual year to year PGR sale dates vary across years, with most in April. However, they can be earlier and associated with store lamb sales (17th February for 2002/2003 season) or later. When using the average PGR data as input to INFORM the sale dates were all in mid-April. The number of lambs sold was higher in 6 of the 10 years by an average of 496 lambs/year, and lower in 4 years by an average 114 lambs, when average rather than actual PGR were used as input into INFORM. Interestingly, in the final year, both situations only sell wether lambs for slaughter (prime) - ewe lambs are sold as breeding ewe replacements.

Figure 3 shows how INFORM allocated ewes to each of the 4 LMUs over the 10 year planning horizon. Interestingly, there appears to be little relationship between ewe allocation and good autumn growth (1997, 2001 and

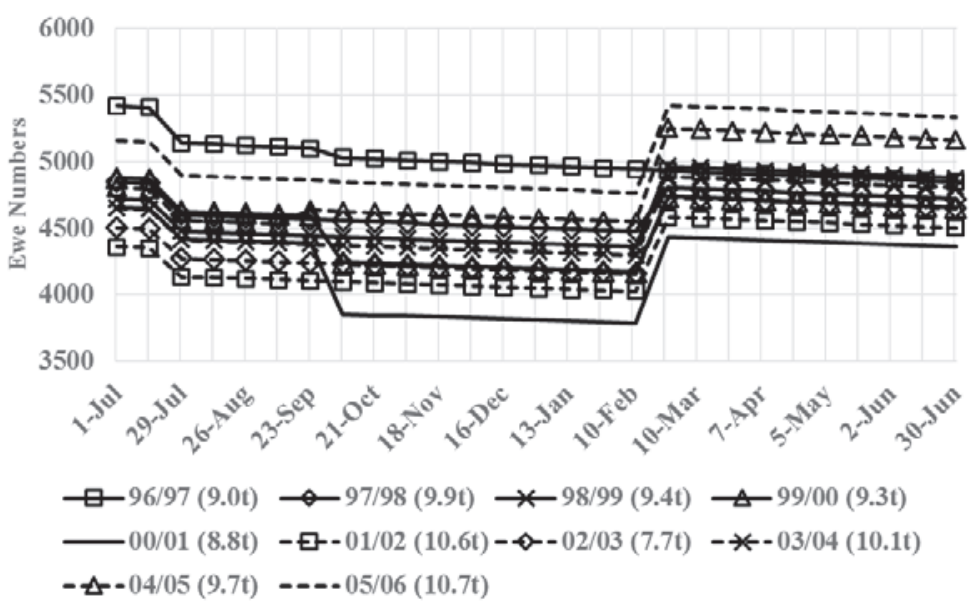

Figure 2a Changes in ewe numbers over the 10 years using actual year to year pasture growth rate data in INFORM.

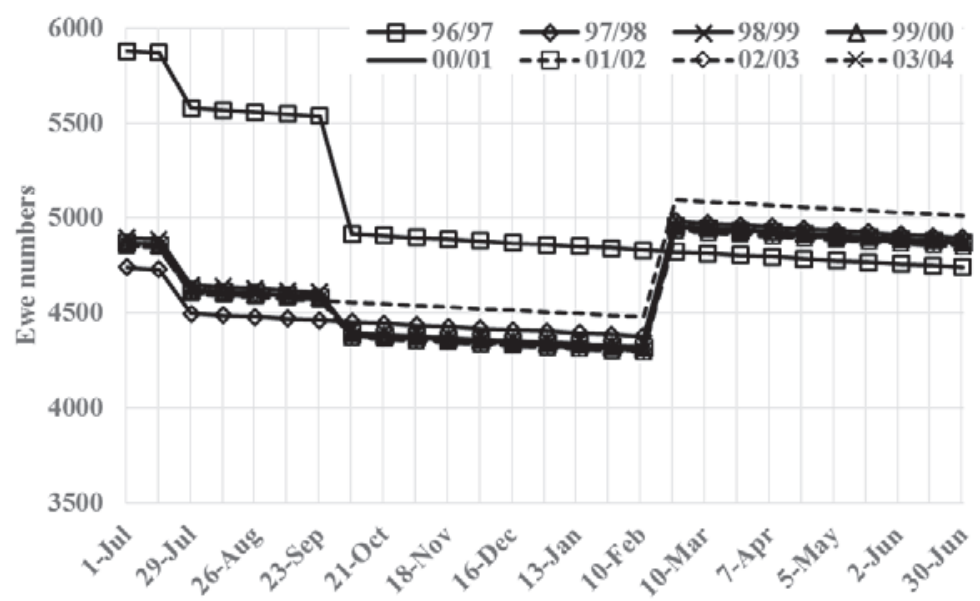

Figure $2 b \quad$ Changes in ewe numbers over the 10 years using average pasture growth rate data in INFORM.

Table 1 Number and average sale date of prime and store lambs for the farm operation using INFORM populated with actual year to year or average pasture growth rates over the 10 year simulation.

\begin{tabular}{|c|c|c|c|c|c|c|c|c|}
\hline & \multicolumn{2}{|c|}{ Actual } & \multicolumn{2}{|c|}{ Average } & \multicolumn{2}{|c|}{ Average - Actual } & \multicolumn{2}{|c|}{ Actual } \\
\hline & Prime Lambs & Date & Prime Lambs & Date & Store Lambs & Days & Store Lambs & Date \\
\hline 1996/1997 & 5921 & 6-Apr. & 6547 & 10-Apr. & 626 & 4 & & \\
\hline 1997/1998 & 5188 & 9-May & 5023 & 16-Apr. & -165 & -23 & & \\
\hline 1998/1999 & 5005 & 13-Apr. & 5235 & 13-Apr. & 230 & 0 & & \\
\hline $1999 / 2000$ & 5256 & 16-Apr. & 5197 & 14-Apr. & -59 & -2 & & \\
\hline $2000 / 2001$ & 5034 & 21-Apr. & 5202 & 14-Apr. & 168 & -7 & & \\
\hline 2001/2002 & 4614 & 25-Apr. & 5202 & 14-Apr. & 588 & -11 & & \\
\hline $2002 / 2003$ & 4222 & 17-Feb. & 5204 & 14-Apr. & 982 & 57 & 648 & 4 Jan. \\
\hline 2003/2004 & 4813 & 4-May & 5197 & 11-Apr. & 384 & -23 & & \\
\hline $2004 / 2005$ & 5212 & 2-Apr. & 5189 & 11-Apr. & -23 & 9 & & \\
\hline $2005 / 2006$ & 3364 & 19-Mar. & 3155 & 4-Apr. & -209 & 16 & & \\
\hline
\end{tabular}




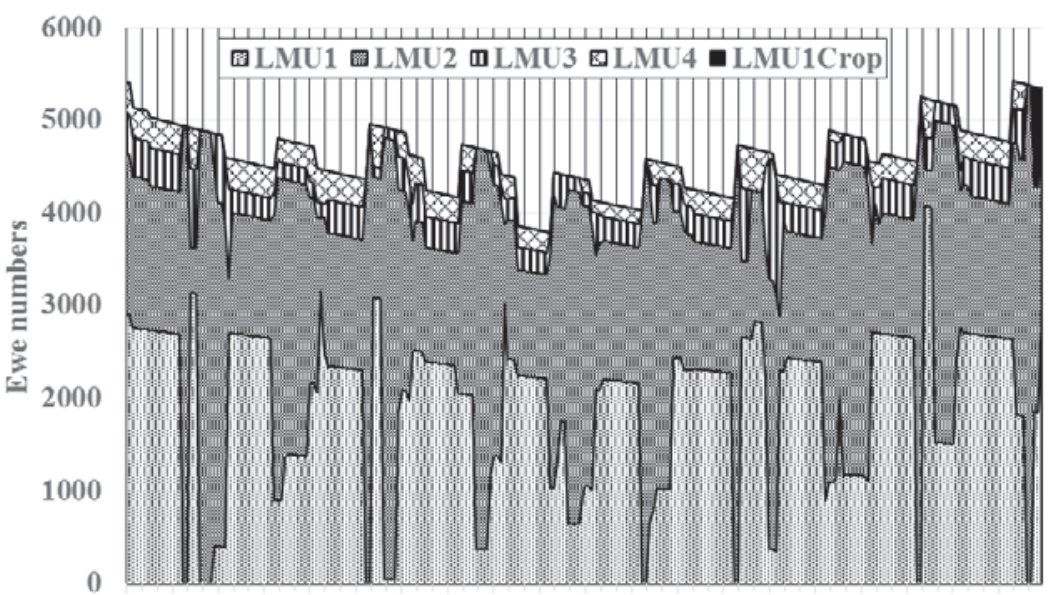

प.

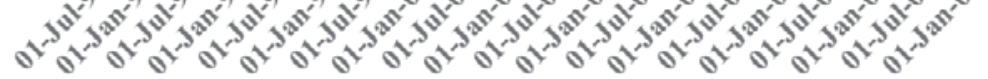

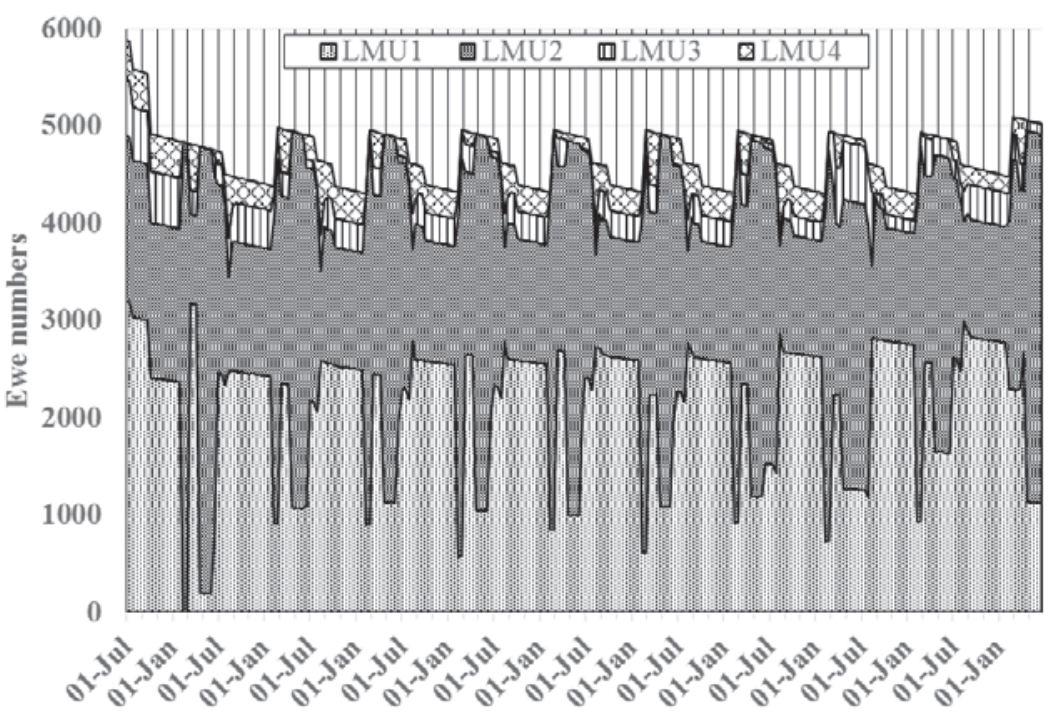

2004) or poor growth (1999, 2001 and 2005). However, it is clear that moving from the use of actual (Figure 3a) to average (Figure 3b) PGR profiles in the multiyear version of INFORM shifts more of the ewe grazing from LMU 1 to 2 .

Beef cow numbers, which were constrained to a minimum of 100 beef cows as at $1^{\text {st }}$ July each year, remain close to that number in both systems, although there was a small sale of pregnant cows mid-October in 1996/1997 (Figure 4). Cow numbers began to increase in late 2002/2003 with the introduction of greater numbers of $\mathrm{R} 2 \mathrm{yr}$ olds into the herd in May, in the farm system modelled using actual year to year pasture production (Figure 4a). Cow numbers continued to increase in this farm system up until sale at the end of 2005/2006 year. This is likely as a result of either the increasing beef cattle feed requirements fitting better with pasture growth over those years, or the greater contribution to the NPV from selling them at the end of the planning
Top:

Figure 3a Stacked ewe numbers on the four land management units (LMU) on the farm system modelled using actual year to year pasture growth rate data in INFORM.

Centre:

Figure 3b Stacked ewe numbers on the four land management units (LMU) on the farm system modelled using average pasture growth rate data in INFORM.

Right:

Table 2
Cattle sold store (weaning) and prime for the farm operation using INFORM populated with actual year to year or average pasture growth rates over the 10 year simulation.

\begin{tabular}{lcccccc}
\hline & \multicolumn{2}{c}{ Store } & & \multicolumn{2}{c}{ Prime } & \\
\cline { 2 - 3 } & Actual & Average & $\begin{array}{l}\text { Average/ } \\
\text { Actual (\%) }\end{array}$ & Actual & Date \\
& & & & & & \\
$1996 / 1997$ & 68 & 68 & & 100 & & \\
$1997 / 1998$ & 66 & 66 & & 100 & & \\
$1998 / 1999$ & 66 & 67 & & 102 & & \\
$1999 / 2000$ & 67 & 67 & & 100 & & \\
$2000 / 2001$ & 28 & 67 & & 239 & & \\
$2001 / 2002$ & 69 & 67 & & 97 & 257 & 4 June \\
$2002 / 2003$ & 56 & 66 & & 118 & & \\
$2003 / 2004$ & 55 & 67 & & 122 & & \\
$2004 / 2005$ & 67 & 62 & & 93 & & \\
$2005 / 2006$ & 153 & 93 & 61 & 5 & 4 June \\
\hline
\end{tabular}


horizon. The contribution of the latter could be tested by selecting the years to include, where 2002/2003 was closer to the start or end of the planning horizon. When average PGR were used in the model cow numbers remain constant over the 10 years, with only a small increase in the final year (Figure 4b), suggesting the increase in cow number in the farm system modelled using actual year to year pasture production (Figure 4a) was more of a reflection of the inter-annual variation, than the 10 year planning horizon.

There was little difference in the numbers of weaners sold between the farm systems modelled using actual year to year or average pasture production for the first 4 years (Table 2). In Year 5 (2001/2002) fewer animals were sold store, the balance being retained as replacement heifers (Appendix 1) when actual year to year pasture growth rates were used to populate the model. Unlike sheep, in the final year no replacements were sold, rather everything was sold store. In 2001/2002 and 2005/2006 store animals were purchased in July and August, respectively, and sold the following June prime in the farm systems modelled using actual year to year pasture growth rate data. The 2001/2002 season had good summer and autumn pasture production, combined with the following year having a poor summer and autumn for pasture growth.

Comparing the timing and amount of nitrogen (N) applied shows the farm system based on average PGR used a fraction of the $\mathrm{N}$ fertiliser applied, up to one quarter less, and the application dates were later into the year of the farm systems modelled using actual year to year PGR (Table 3).

50

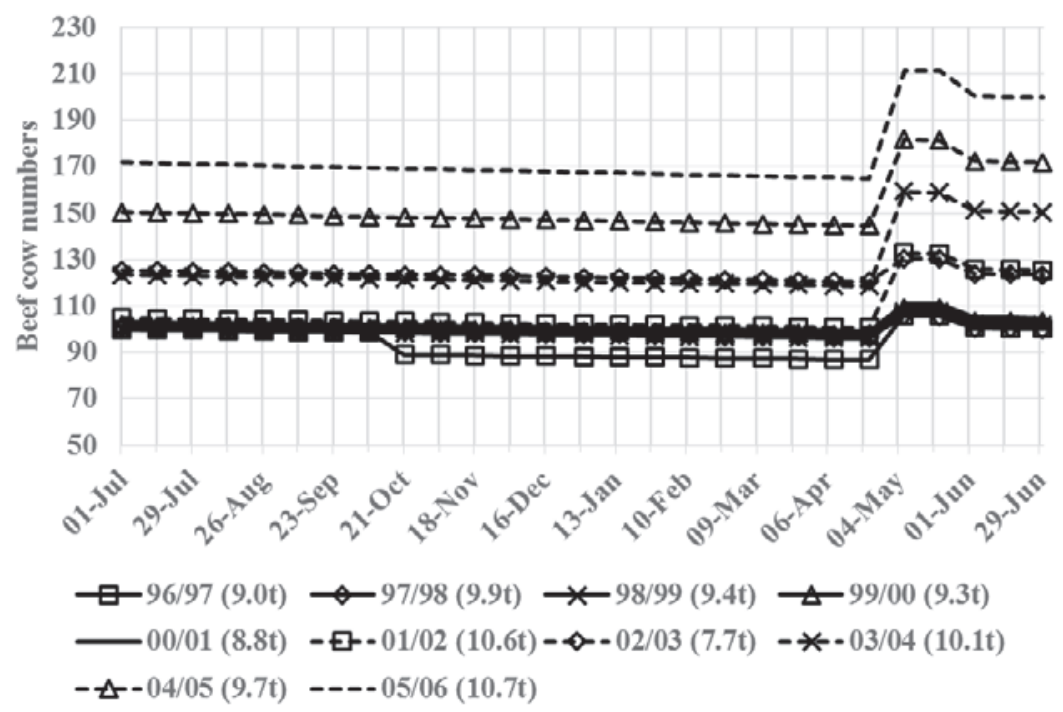

Figure 4a Change in beef cow numbers over the 10 years using actual year to year pasture growth rate data in INFORM.

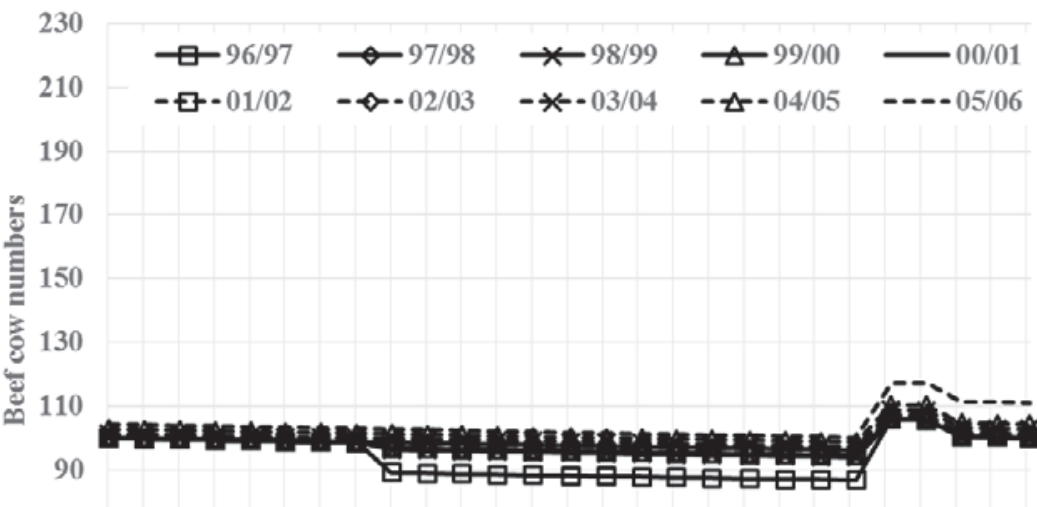

Figure 4b Change in beef cow numbers over the 10 years using average pasture growth rate data in INFORM.

Pasture covers were different between the farm system modelled with actual year to year (Figure 5a) and average (Figure 5b) PGR data. Both systems start with high pasture covers at the start of the planning horizon (July 1996). The system modelled with actual year to year pasture growth rate data had minimum covers (1500 kg DM/ha; average over a LMU) reached between April and mid-October, and peak covers $(2500 \mathrm{~kg} \mathrm{DM} /$ ha) reached anywhere between January and April. In contrast, with average pasture growth data the minimum pasture covers were reached between mid-June and mid-September and maximum covers over January in 


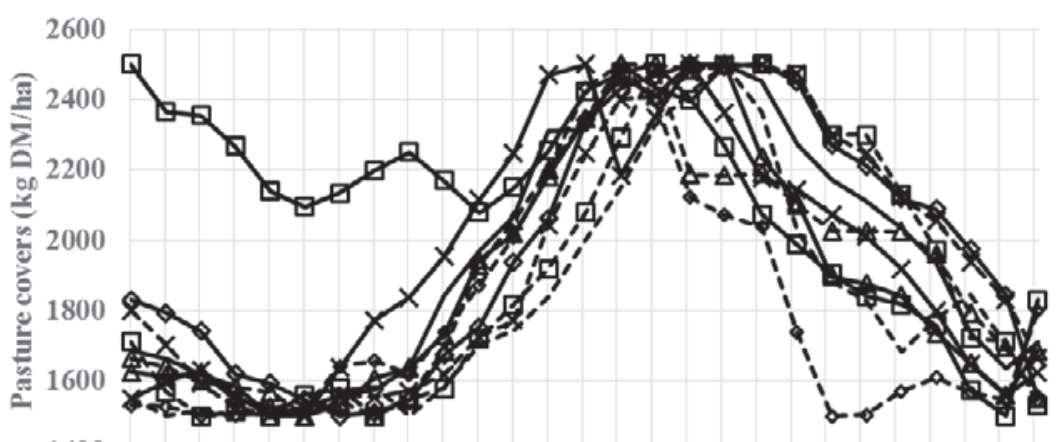

1400
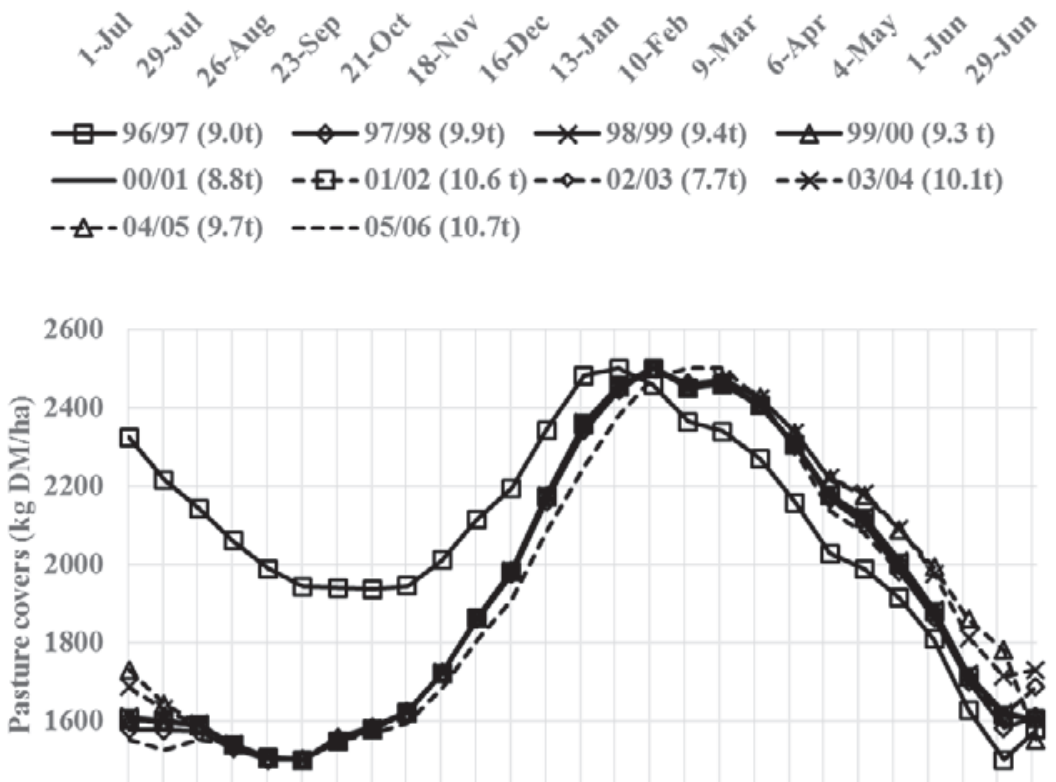

1400

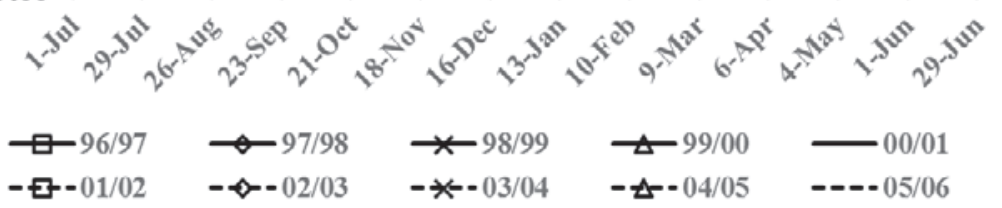

the first year, February in subsequent years with the exception of the final year when it was March.

INFORM elected to plant 21 ha of winter crop in the final year $(2005 / 2006)$ of the planning horizon on the farm system modelled using actual PGR. This was used for ewes and cattle, presumably because the additional marginal revenue from selling capital stock was greater than the marginal cost of planting a crop. A small amount of supplementary feed (hay or silage; 9.7t DM) was made in December 2004 and fed out in February 2005.

\section{Financial}

The initial capital investment in livestock and annual EBITDA's was higher when using an average PGR than when using actual year to year PGR (Table 4). In Years 3 and 5 of the 10 years there was more than a 20 and $10 \%$ difference in performance, respectively, when comparing the outcome from the farm operation based on average compared with actual year to year PGR. The
Top:

Figure 5a Fortnightly pasture covers ( $\mathrm{kg}$ DM/ha) over each of the 10 years averaged for the four land management units simulated by the multiyear version of INFORM using actual year to year pasture growth data.

Centre:

Figure 5b Fortnightly pasture covers ( $\mathrm{kg}$ DM/ha) over each of the 10 years averaged for the four land management units simulated by the multiyear version of INFORM using average pasture growth data.

Right:

Table 3
Amount (tonnes) and timing of nitrogen fertiliser application for the farm operation using INFORM populated with actual year to year or average pasture growth rates over the 10 year simulation.

\begin{tabular}{lrrrrr}
\hline & \multicolumn{2}{c}{ Actual } & & \multicolumn{2}{c}{ Average } \\
\cline { 2 - 3 } \cline { 5 - 6 } & Amount & Date & & Amount & Date \\
\hline $1996 / 1997$ & 9.6 & 8-Apr. & & 9.6 & 12-Apr. \\
$1997 / 1998$ & 10.8 & 19-Mar. & & 0.0 & \\
$1998 / 1999$ & 9.6 & 17-Jun. & & 9.6 & 17-Jun. \\
$1999 / 2000$ & 19.2 & 13-May & & 9.6 & 17-Jun. \\
$2000 / 2001$ & 21.5 & 9-Mar. & 9.6 & 17-Jun. \\
$2001 / 2002$ & 23.4 & 16-Mar. & 9.6 & 17-Jun. \\
$2002 / 2003$ & 28.8 & 8-Apr. & 9.6 & 17-Jun. \\
$2003 / 2004$ & 12.5 & 7-May & & 10.9 & 8-Jun. \\
$2004 / 2005$ & 36.2 & 3-Feb. & 9.5 & 23-May \\
$2005 / 2006$ & 23.0 & 11-Jan. & 19.2 & 3-Dec. \\
\hline & & & & & \\
\hline
\end{tabular}


greatest overestimation was for a year with a prolonged summer/autumn drought (2003), followed by a February drought (2005). The NPV over the 10 years and its derived annuity, were only overestimated by $5 \%$ using average instead of actual year to year PGR. However, the coefficient of variation of EBITDA, excluding the opening (1996/1997) and closing (2005/2006) seasons (these were unusual as they were the start-up and exiting seasons) was $25 \%$ using actual year to year PGR and $2 \%$ using average PGR.

\section{Discussion}

It is important to note when examining the outputs of the multi-year version of INFORM that all the information over the 10 year simulation was known in advance of the analysis. While forecasting weather patterns into the future still has low confidence intervals, the analytical capability to investigate the impact that climatic variation has on the business has advantages, as does the ability to explore pathways after a perturbation due, for example, to an extreme climatic event.

This analysis does not include meat or wool price variability due to supply and demand pressures or other market forces or the impact pasture covers and expected PGR have on the grass and store stock markets and prices. These combined with pasture growth variation have the potential to create a "perfect storm" where

Table 4

Initial capital investment in livestock and annual EBITDA's for the farm operation using INFORM populated with actual year to year or average pasture growth rates over the 10 year simulation.

\begin{tabular}{lccc}
\hline Year & Actual (\$) & Average (\$) & Difference (\%) \\
\hline Initial $^{1}$ & 1022920 & 1085890 & 6.2 \\
$1996 / 1997$ & 436113 & 539423 & 23.7 \\
$1997 / 1998$ & 398999 & 333650 & -16.4 \\
$1998 / 1999$ & 313218 & 350061 & 11.8 \\
$1999 / 2000$ & 361076 & 344779 & -4.5 \\
$2000 / 2001$ & 335406 & 345620 & 3.0 \\
$2001 / 2002$ & 346064 & 345480 & -0.2 \\
$2002 / 2003$ & 150042 & 345318 & 130.1 \\
$2003 / 2004$ & 319734 & 338408 & 5.8 \\
$2004 / 2005$ & 245709 & 337698 & 37.4 \\
$2005 / 2006^{2}$ & 1475210 & 1316040 & -10.8 \\
Final $^{3}$ & 1354150 & 1196090 & -11.7 \\
NPV $^{2}$ & 2230070 & 2345210 & 5.2 \\
Annuity $_{\text {EBITDA CV }}{ }_{2-9}{ }^{4}$ & 288804 & 303715 & 5.2 \\
\hline
\end{tabular}

${ }^{1}$ Capital value livestock beginning planning horizon

2 Includes final value of livestock

${ }^{3}$ Capital value livestock at end of planning horizon

${ }^{4}$ Coefficient of Variation 1997/1998 to 2004/2005 low prices occur in years with low pasture production. The ability to explore the impact this has on the farm system would be of interest to institutions that fund farm purchases, as the probability of a low profit year in the first 5 years into the planning horizon could be estimated and provisions made in the loan agreement.

What was evident from the results of this comparison was that ignoring the variation in pasture growth across years by limiting analysis to the use of a long-term average annual PGR only, seriously constrains the insights farm systems analysis can provide to not only the practitioners, but also to their agents. In this study shifting from average to actual year to year PGR data input to the multi-year version of INFORM resulted in changes in capital stock numbers, the numbers of livestock produced for sale and the timing of sales. Interestingly, the stock numbers for the average analysis varied at the beginning and end of the planning horizon and were similar throughout the middle years. This may be due to the discounting of EBITDA and accounting for the capital value of livestock at the beginning and end of the planning horizon. It also highlighted that use of average growth rates may lead to conceptualising and, more concerning, farmers trying to implement an over-ambitious system that will not work at the level of performance indicated. In the case of the Whanganui farm, the systems modelled using average PGR data had higher stocking rates and lamb sales, predicted less variability in prime lamb sale number and dates, lower $\mathrm{N}$ fertiliser usage and a higher EBITDA than the farm systems model using actual year to year PGR data.

Interestingly, the farm system modelled using actual year to year PGR data slowly increased beef cow numbers over the last few years of the planning horizon. This was a potential opportunity not available when analysis was limited to the use of average PGR data. It would also appear from the analysis that using averages rather than actual year to year PGR resulted in a more complex system than needed. These results also cast doubt on the merits of using an average year for farm performance benchmarking and sticking rigidly to target pasture covers (Figure 5).

As expected, EBITDA was substantially more variable across years when actual year to year PGR data were used rather than average. The CV of the system reported by Cacho \& Bywater (1994) was 10\%, compared with $25 \%$ in this study. The lower estimate from Cacho \& Bywater (1994) may be due to: (i) their system being based on irrigated pasture, hence the variability of PGR across years is likely to be less; (ii) simulated approach compared with an optimisation approach.

This analysis may not have captured the benefit of beef cows as effectively as it could have. When they were not suckling calves beef cows can consume poor quality feed, and continue to maintain themselves. By 
modifying INFORM to allow pasture covers to go higher and suppressing future PGR (i.e. herbage accumulation), and only allowing cattle to graze above a certain cover would increase understanding of the buffering capacity that exists in hill country farms. This in turn could influence the direction of research.

The different numbers of capital stock on farm over the years when actual year to year or average pasture data was used, leads to questioning the current practice of using average pasture production (or indeed farm systems) in evaluating the potential or impact of research at the farm level. Further, due to the variation in the flow of livestock sales between years when actual pasture growth data was used, perhaps better understanding the impact of inter-annual variation in pasture production on the red meat supply chain, is also warranted. The planning horizon of 10 years was probably too short and should have been 20 years. Due to discounting, this would lessen the influence that sale of stock at the end of the planning horizon had on the farm systems in the last 12 months as was evident in both cattle policy on both systems (Figure 4).

One of the challenges with the multi-year farm optimisation model is summarising the large volume of outputs from across all land management units. A picture of the key components of the farm system needs to be clearly painted both within and across years, in such a way as to inform discussion.

\section{Conclusions}

There was a difference in farm system design over a 10 year planning horizon, when actual year to year rather than average pasture production data were used in the analysis. While this leads to a small change in annuity, there were large swings in annual EBITDA between years. There were also differences in stock numbers and sale dates. Therefore, on-farm decisions around stocking rate and sale dates will be different when actual year to year pasture growth rates were used over time, rather than average. This has implications to evaluating the benefits or gaps in research, as well as to the supply chain.

\section{ACKNOWLEDGEMENTS}

Dougal and Di McIntosh for willingly allowing us to base our analysis on their property and for the amazing discussions we have had. Pasture 21 consortium for providing the funding that allowed us to begin to explore the impact of using multiyear data on farm system design. The two anonymous referees who made constructive suggestions.

\section{REFERENCES}

Bourdôt, G.; King, W.; Rennie, G. 2012. Giant Buttercup - modelling the financial benefits of control on a Golden Bay dairy farm. Proceedings of the New Zealand Grasslands Association 74: 177182.

Cacho, O.J.; Bywater, A.C. 1994. Use of a grazing model to study management and risk. Proceedings of the New Zealand Society Animal Production 54: 377-381.

Chapman, D.F.; Bryant, J.R.; Kerr, G.A.; Judson, G.; Cookson, T.; Edwards, G.E.; McMillan, W.H. 2013. Economic values for perennial ryegrass traits in New Zealand dairy farm systems. Proceedings of the $22^{\text {nd }}$ International Grasslands Conference. pp. 822-823.

Dynes, R.A.; Smeaton, D.C.; Rhodes, A.P.; Fraser, T.J.; Brown, M.A. 2011. Modelling farm management scenarios that illustrate opportunities farmers have to reduce greenhouse gas emissions while maintaining profitability. Proceedings of the New Zealand Society Animal Production 71: 167-171.

Korte, C.J.; Rhodes, A.P. 1993. Economics of droughttolerant pastures for cattle finishing on Hawkes Bay and Wairarapa hill country farms. Proceedings of the New Zealand Grasslands Association 55: 45-49.

Lynn, I.H.; Manderson, A.K.; Page, M.J.; Harmsworth, G.R.; Eyles, G.O.; Douglas, G.B.; Mackay, A.D.; Newsome, P.J.F. 2009. Land use capability survey hand-book: A New Zealand handbook for the classification of land. 3rd ed., pp.163. AgResearch, Hamilton; Landcare Research, Lincoln and Institute Geological and Nuclear Science, Lower Hutt, New Zealand.

Thompson, B.R.; Stevens, D.R.; Bywater, A.C.; Rendel, J.M.; Cox, N.R. 2015. Impacts of animal genetic gain on the profitability of three different grassland farming systems producing red meat. Agricultural Systems 141: 36-47.

Vibart, R.E.; Douglas, G.B.; Mackay, A.D.; Dodd, M.B.; McIvor, I.R. 2015. Pasture-tree systems - Modelling potential implications for animal performance and greenhouse gas emissions. Journal of New Zealand Grasslands 77: 153-158.

Vogeler, I.; Mackay, A.; Vibart, R.; Rendel, J.; Beautrais, J.; Dennis, S. 2016. Effect of inter-annual variability in pasture growth and irrigation response on farm productivity and profitability based on biophysical and farm systems modelling. Science of the Total Environment 565: 564-575. 
Appendix 1

Number ewes and ewe hoggets on farm annually as at $1^{\text {st }}$ July (start of financial year).

\begin{tabular}{|c|c|c|c|c|c|c|}
\hline & \multicolumn{3}{|c|}{ Ewes } & \multicolumn{3}{|c|}{ Ewe Hoggets } \\
\hline & Actual & Average & $\begin{array}{c}\text { Average/ } \\
\text { Actual (\%) }\end{array}$ & Actual & Average & $\begin{array}{c}\text { Average/ } \\
\text { Actual (\%) }\end{array}$ \\
\hline $1996 / 1997$ & 5416 & 5880 & 109 & 1110 & 1086 & 98 \\
\hline 1997/1998 & 4848 & 4739 & 98 & 1110 & 1086 & 98 \\
\hline $1998 / 1999$ & 4721 & 4896 & 104 & 1081 & 1122 & 104 \\
\hline $1999 / 2000$ & 4876 & 4868 & 100 & 1117 & 1115 & 100 \\
\hline $2000 / 2001$ & 4655 & 4872 & 105 & 1066 & 1116 & 105 \\
\hline 2001/2002 & 4359 & 4871 & 112 & 998 & 1116 & 112 \\
\hline $2002 / 2003$ & 4503 & 4872 & 108 & 1031 & 1116 & 108 \\
\hline $2003 / 2004$ & 4651 & 4864 & 105 & 1065 & 1114 & 105 \\
\hline $2004 / 2005$ & 4805 & 4857 & 101 & 1205 & 1113 & 92 \\
\hline $2005 / 2006$ & 5160 & 4850 & 94 & 1182 & 1111 & 94 \\
\hline Sold & 5330 & 5010 & 94 & 3323 & 3123 & 94 \\
\hline
\end{tabular}

Ewes sold (dry culls 26 July, culls 19 Feb, ewes with lambs 7 Oct) and ewes purchased.

\begin{tabular}{|c|c|c|c|c|c|c|c|c|}
\hline & \multicolumn{4}{|c|}{ Sold } & \multicolumn{4}{|c|}{ Purchased } \\
\hline & Actual & Date & Average & Date & Actual & Date & Average & Date \\
\hline \multirow[t]{3}{*}{$1996 / 1997$} & 257 & 26 Jul. & 279 & 26 Jul. & & & & \\
\hline & 61 & 7 Oct. & 609 & 7 Oct. & & & & \\
\hline & 1075 & 19 Feb. & 1051 & 19 Feb. & & & & \\
\hline \multirow[t]{3}{*}{$1997 / 1998$} & 230 & 26 Jul. & 225 & 26 Jul. & & & & \\
\hline & & 7 Oct. & & 7 Oct. & & & & \\
\hline & 740 & 19 Feb. & 438 & 19 Feb. & & & & \\
\hline \multirow[t]{3}{*}{$1998 / 1999$} & 224 & 26 Jul. & 232 & 26 Jul. & & & & \\
\hline & & 7 Oct. & 219 & 7 Oct. & & & & \\
\hline & 436 & 19 Feb. & 431 & 19 Feb. & & & & \\
\hline \multirow[t]{3}{*}{$1999 / 2000$} & 231 & 26 Jul. & 231 & 26 Jul. & & & & \\
\hline & 339 & 7 Oct. & 180 & 7 Oct. & & & & \\
\hline & 507 & 19 Feb. & 432 & 19 Feb. & & & & \\
\hline \multirow[t]{3}{*}{$2000 / 2001$} & 221 & 26 Jul. & 231 & 26 Jul. & & & & \\
\hline & 518 & 7 Oct. & 186 & 7 Oct. & & & & \\
\hline & 379 & 19 Feb. & 432 & 19 Feb. & & & & \\
\hline \multirow[t]{3}{*}{$2001 / 2002$} & 207 & 26 Jul. & 231 & 26 Jul. & & & & \\
\hline & & 7 Oct. & 185 & 7 Oct. & & & & \\
\hline & 402 & 19 Feb. & 432 & 19 Feb. & & & & \\
\hline \multirow[t]{3}{*}{$2002 / 2003$} & 214 & 26 Jul. & 231 & 26 Jul. & & & & \\
\hline & & 7 Oct. & 194 & 7 Oct. & & & & \\
\hline & 416 & 19 Feb. & 431 & 19 Feb & & & & \\
\hline \multirow[t]{3}{*}{$2003 / 2004$} & 221 & 26 Jul. & 231 & 26 Jul. & & & & \\
\hline & & 7 Oct. & 194 & 7 Oct. & & & & \\
\hline & 429 & 19 Feb. & 430 & 19 Feb. & & & & \\
\hline \multirow[t]{3}{*}{$2004 / 2005$} & 228 & 26 Jul. & 230 & 26 Jul. & & 23 Sept. & & \\
\hline & & 7 Oct. & 193 & 7 Oct. & 113 & & & \\
\hline & 455 & 19 Feb. & 430 & 19 Feb. & & & & \\
\hline \multirow[t]{4}{*}{$2005 / 2006$} & 245 & 26 Jul. & 230 & 26 Jul. & & & & \\
\hline & & 7 Oct. & 609 & 7 Oct. & & & & \\
\hline & 476 & 19 Feb. & 448 & 19 Feb. & & & & \\
\hline & 5330 & 30 Jun. & 5010 & 30 Jun. & & & & \\
\hline
\end{tabular}


Number beef cows and replacement R1yr olds $1^{\text {st }}$ July (start of financial year).

\begin{tabular}{|c|c|c|c|c|c|c|}
\hline & \multicolumn{3}{|c|}{ Cows (including 2 year olds) } & \multicolumn{3}{|c|}{ R1yr replacements } \\
\hline & Actual & Average & $\begin{array}{c}\text { Average/ } \\
\text { Actual (\%) }\end{array}$ & Actual & Average & $\begin{array}{c}\text { Average/ } \\
\text { Actual (\%) }\end{array}$ \\
\hline $1996 / 1997$ & 100 & 100 & 100 & 20 & 20 & 100 \\
\hline $1997 / 1998$ & 100 & 100 & 100 & 20 & 20 & 100 \\
\hline $1998 / 1999$ & 100 & 100 & 100 & 22 & 22 & 100 \\
\hline $1999 / 2000$ & 102 & 100 & 98 & 22 & 22 & 100 \\
\hline $2000 / 2001$ & 103 & 100 & 97 & 23 & 22 & 96 \\
\hline $2001 / 2002$ & 105 & 100 & 95 & 44 & 22 & 50 \\
\hline $2002 / 2003$ & 125 & 100 & 80 & 23 & 22 & 96 \\
\hline $2003 / 2004$ & 123 & 101 & 82 & 55 & 22 & 40 \\
\hline 2004/2005 & 151 & 103 & 68 & 54 & 23 & 43 \\
\hline 2005/2006 & 172 & 104 & 60 & 66 & 29 & 44 \\
\hline Sold & 200 & 110 & 55 & 0 & 0 & \\
\hline
\end{tabular}

